\title{
SISTEM PRESENSI KELAS MENGGUNAKAN PENGENALAN WAJAH DENGAN METODE HAAR CASCADE CLASSIFIER
}

\author{
Rastri Prathivi \\ Fakultas Teknologi Informasi dan Komunikasi, Program Studi Teknik Informatika \\ Universitas Semarang \\ Email: ftik@usm.ac.id \\ Yunita Kurniawati \\ Fakultas Teknologi Informasi dan Komunikasi, Program Studi Teknik Informatika \\ Universitas Semarang \\ Email: Yunita6.yk@gmail.com
}

\begin{abstract}
ABSTRAK
Kehadiran siswa di kelas merupakan hal penting saat kegiatan belajar mengajar di laksanakan. Sistem presensi yang masih menggunakan cara manual dengan memakai kertas. Memiliki permasalahan yang sering muncul antara lain: terjadinya manipulasi data kehadiran, hilangnya buku presensi, sulit dalam merekapitulasi data kehadiran. Sistem presensi dengan pengenalan wajah digunakan karena hanya memerlukan kamera untuk mengambil citra gambar. Dengan mengotomatiskan proses kehadiran akan lebih meningkatkan produktivitas guru kepada siswanya. Metode haar cascade classifier digunakan karena memiliki komputasi yang sangat cepat tergantung pada jumlah piksel dalam persegi bukan nilai piksel dari sebuah gambar. Dari hasil pendeksian wajah menggunakan metode haar cascade classifier prosentase yang telah dicapai sebesar $75 \%$. Seluruh sistem terbukti dapat berjalan dengan baik dalam mendeteksi seluruh objek yang ada secara tepat. Sistem memudahkan dalam memantau kehadiran siswadi kelas secara akurat, efisien serta menghemat waktu serta tenaga.
\end{abstract}

Kata kunci: presensi; haar cascade classifier.

\section{ABSTRACT}

The presence of students in class is important when teaching and learning activities are carried out. Presence system that still uses the manual method using paper. Having problems that often arise include: the presence of manipulation of attendance data, the absence of attendance books, the difficulty in recapitulating attendance data. A face recognition presence system is used because it only requires a camera to take pictures. Automating the attendance process will further increase teacher productivity for students. The haar cascade classifier method is used because it has very fast computation depending on the number of pixels in a square rather than the pixel value of an image.From the results of facial detection using the haar cascade classifier method the percentage achieved was $75 \%$. The entire system is proven to work well in detecting all existing objects precisely. The system makes it easy to monitor the attendance of class students accurately, efficiently and saves time and effort.

Keywords: presence; haar cascade classifier.

\section{PENDAHULUAN}

\subsection{Latar Belakang}

Kehadiran siswa di kelas merupakan hal penting saat kegiatan belajar mengajar di laksanakan. Sistem presensi yang masih menggunakan cara manual dengan memakai kertas. Hal tersebuat termasuk mebuang-buang waktu produktivitas belajar. Wajah adalah bukti penting yang bisa digunakan untuk sistem presensi. Metode pengenalan wajah yang digunakan dalam sistem presensi kelas adalah dengan metode haar cascade classifier karena metode haar cascade classifier mempunyai kelebihan yaitu komputasi yang sangat cepat, karena hanya tergantung pada jumlah piksel dalam persegi bukan setiap nilai piksel dari sebuah image.

\subsection{Batasan Masalah}

Agar pembahasan masalah menjadi lebih jelas dan terarah, makan diperlukannya adanya batasan masalah. Adapun ruang lingkup dalam susunan ini dibatas pada: 
a. Sistem ini hanya mengelola kehadiran siswa saja.

b. Metode yang digunakan adalah metode haar cascade classifier.

c. Sistem yang dikelola menggunakan sistem pengembangan prototype.

d. Pembuatan sistem menggunakan raspberry pi.

e. Bahasa pemrograman menggunakan python.

f. Sistem kami nantinya memiliki 3 fase yaitu : deteksi wajah dan pengumpulan data, latihan pengenalan wajah, pengenalan wajah.

g. Sistem tidak dapat mengenali wajah siswa dengan baik dalam cahaya redup, sistem hanya dapat mendeteksi dari jarak kurang lebih 1 meter.

\section{LANDASAN TEORI}

\subsection{Sistem Presensi}

Suatu pendataan kehadiran yang merupakan bagian dari aktifitas pelaporan yang ada pada suatu instansi. Absensi disusun dan diatur sehingga mudah untuk dicari dan dipergunakan ketika diperlukan oleh pihak yang berkepentingan.

\subsection{Sistem Kerja Algoritma Haar Cascade Classifier}

Algoritma Haar menggunakan metode statistical dalam melakukan pendeteksian wajah. Metode ini menggunakan sample haarlike fetures. Classifier ini menggunakan gambar berukuran tetap (umumnya berukuran $24 \times 24$ ). Cara kerja dari haar dalam mendeteksi wajah adalah dengan menggunakan teknik sliding window berukuran 24x24 pada keseluruhan gambar dan mencari apakah terdapat bagian dari gambar yang berbentuk seperti wajah atau tidak. Haar juga memiliki kemampuan untuk melakukan scaling sehingga dapat mendeteksi adanya wajah yang berukuran lebih besar ataupun lebih kecil dari gambar pada classifier. Tiap feature dari haar-like feature didefinisikan pada bentuk dari feaature, diantaranya koordinat dari feature dan juga ukuran dari feature tersebut.

\subsection{Haar Feature}

Haar Feature adalah fitur yang didasarkan pada Wavelet Haar. Wavelet Haar adalah gelombang tunggal bujur sangkar (satu interval tinggi dan satu interval rendah). Untuk dua dimensi, satu terang dan satu gelap. Selanjutnya kombinasikombinasi kotak yang digunakan untuk pendeteksian objek visual yang lebih baik. Setiap Haar-like feature terdiri dari gabungan kotak - kotak hitam dan putih.

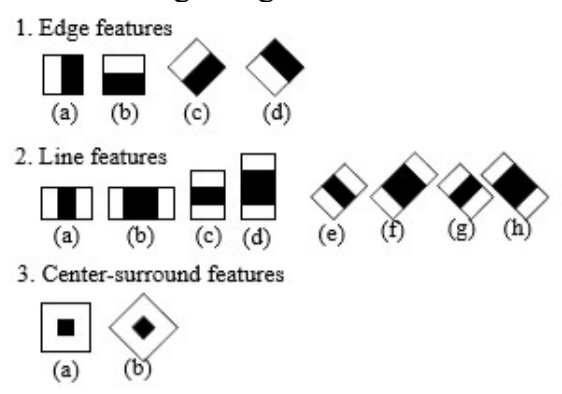

Gambar 1. Macam-Macam Variasi Feature Pada Haar (Viola, 2001)

3 tipe $\operatorname{kotak}($ rectangular $)$ feature:

1. Tipe two-rectangle feature (horisontal/vertikal)

2. Tipe three-rectangle feature

3. Tipe four-rectangle feature

Adanya fitur Haar ditentukan dengan cara mengurangi rata-rata piksel pada daerah gelap dari ratarata piksel pada daerah terang. Jika nilai perbedaannya itu diatas nilai ambang atau treshold, maka dapat dikatakan bahwa fitur tersebut ada. Nilai dari Haar-like feature adalah perbedaan antara jumlah nilai-nilai piksel gray level dalam daerah kotak hitam dan daerah kotak putih:

$\mathcal{F}(x)=$ SumBlack rectangle - SumWhite rectangle

Keterangan : dimana untuk kotak pada Haar-like feature dapat dihitung secara cepat menggunakan "integral image". 


\section{$2.4 \quad$ Integral Image}

Integral Image digunakan untuk menentukan ada atau tidaknya dari ratusan fitur Haar pada sebuah gambar dan pada skala yang berbeda secara efisien. Pada umumnya, pengintegrasian tersebut berarti menambahkan unit-unit kecil secara bersamaan. Dalam hal ini unit-unit kecil tersebut adalah nilai-nilai piksel. Nilai integral untuk masing-masing piksel adalah jumlah dari semua piksel-piksel dari atas sampai bawah. Dimulai dari kiri atas sampai kanan bawah, keseluruhan gambar itu dapat dijumlahkan dengan beberapa operasi bilangan bulat per piksel.

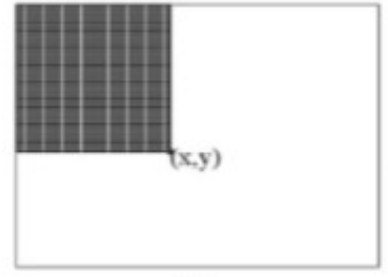

(a)

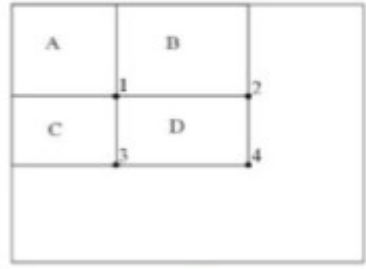

(b)

Gambar 2. Integral Image (Viola, 2001)

Seperti yang ditunjukkan oleh gambar (a) di atas setelah pengintegrasian, nilai pada lokasi piksel $(\mathrm{x}, \mathrm{y})$ berisi jumlah dari semua piksel di dalam daerah segiempat dari kiri atas sampai pada lokasi $(\mathrm{x}, \mathrm{y})$ atau daerah yang diarsir. Guna mendapatkan nilai rata-rata piksel pada area segiempat (daerah yang diarsir) ini dapat dilakukan hanya dengan membagi nilai pada $(\mathrm{x}, \mathrm{y})$ oleh area segiempat.

$$
\mathrm{ii}(\mathrm{x}, \mathrm{y})=\sum_{x^{7} \leq x, y, s y} i\left(x^{b}, y^{\prime}\right)
$$

Keterangan :

ii $(\mathrm{x}, \mathrm{y})=$ Citra integral pada lokasi $\mathrm{x}, \mathrm{y}$

$\mathrm{i}\left(\mathrm{x}^{\prime}, \mathrm{y}^{\prime}\right)=$ nilai piksel pada citra asli

Guna mengetahui nilai piksel untuk beberapa segiempat yang lain, seperti segiempat D pada gambar (b), dapat dilakukan dengan cara menggabungkan jumlah piksel pada area segiempat $\mathrm{A}+\mathrm{B}+\mathrm{C}+\mathrm{D}$, dikurangi jumlah dalam segiempat $\mathrm{A}+\mathrm{B}$ dan $\mathrm{A}+\mathrm{C}$, ditambah jumlah piksel di dalam $\mathrm{A}$. Dengan, $\mathrm{A}+\mathrm{B}+\mathrm{C}+\mathrm{D}$ adalah nilai dari integral image pada lokasi $4, \mathrm{~A}+\mathrm{B}$ adalah nilai pada lokasi $2, \mathrm{~A}+\mathrm{C}$ adalah nilai pada lokasi 3, dan A pada lokasi 1. Sehingga hasil dari D dapat dikomputasikan.

$\mathrm{D}=(\mathrm{A}+\mathrm{B}+\mathrm{C}+\mathrm{D})-(\mathrm{A}+\mathrm{B})-(\mathrm{A}+\mathrm{C})+\mathrm{A}$

\subsection{Cascade Classifier}

Cascade classifier adalah sebuah rantai stage classifier, dimana setiap stage classifier digunakan untuk mendeteksi apakah didalam image sub window terdapat obyek yang diinginkan (object of interest). Stage classifier dibangun dengan menggunakan algoritma adaptive-boost (AdaBoost). Algoritma tersebut mengkombinasikan performance banyak weak classifier untuk menghasilkan strong classifier. Weak classifier dalam hal ini adalah nilai dari haar-like feature. Jenis AdaBoost yang digunakan adalah Gentle AdaBoost.

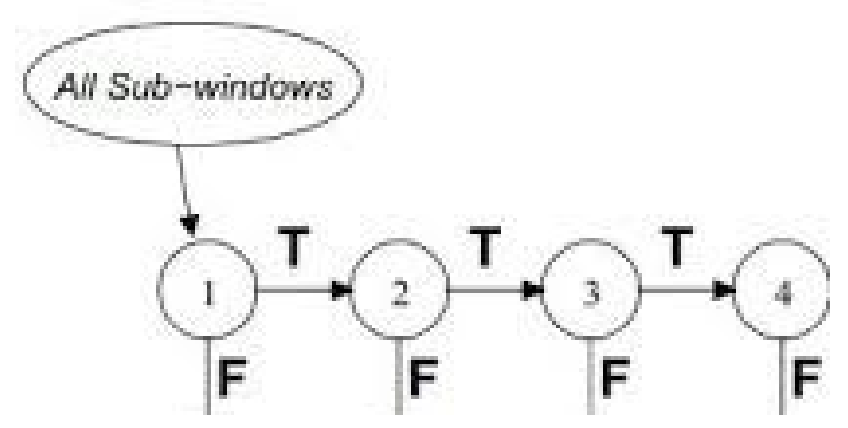

Gambar 3. Model Classifier Secara Cascade (Viola, 2001) 


\section{METODE}

\subsection{Menghitung Sampel Haar Feature}

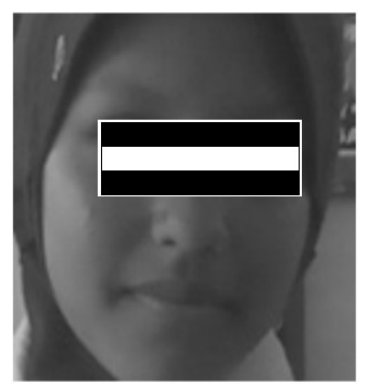

\section{Gambar 4. Sampel Haar Feature}

Cara menghitung sampel haar feature adalah kotak hitam dikurangi kotak putih, sebelum dikurangi kotak hitam maka dijumlahkan terlebih dahulu antar kotak hitam yang telah dibagi menjadi 3 bagian begitu pulan dengan kotak putih, setelah semuanya dijumlahkan baru lah keduanya dikurangkan.

\begin{tabular}{|l|l|l|}
\hline 2 & 3 & 4 \\
\hline 3 & 4 & 5 \\
\hline 5 & 6 & 2 \\
\hline
\end{tabular}

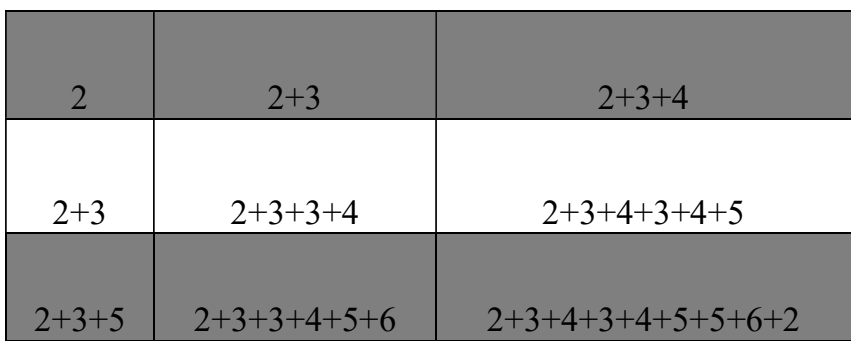

Maka hasil perhitungan adalah :

Nilai fitur $=(16+67)-38=45$

\begin{tabular}{|l|l|l|}
\hline 2 & 3 & 4 \\
\hline 3 & 4 & 5 \\
\hline 5 & 6 & 2 \\
\hline
\end{tabular}

\subsection{Menghitung Intrgral Image}

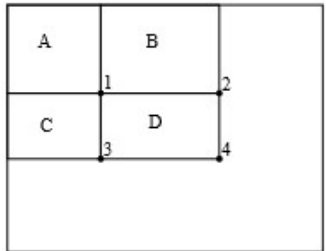

Cara menghitung integral image adalah menjumlahkan kotak A,B,C,D lalu dikurangi kotak A dijumlahkan kotak $\mathrm{B}$, setelah itu kurangi lagi kotak $\mathrm{A}$ yang telah dijumlah kotak $\mathrm{C}$ dan akhirnya dijumlahkan kotak A.

$$
\begin{aligned}
\mathrm{D} & =(\mathrm{A}+\mathrm{B}+\mathrm{C}+\mathrm{D})-(\mathrm{A}+\mathrm{B})-(\mathrm{A}+\mathrm{C})+\mathrm{A} \\
& =4-2-3+4 \\
& =3
\end{aligned}
$$




\subsection{Cascade Classifier}

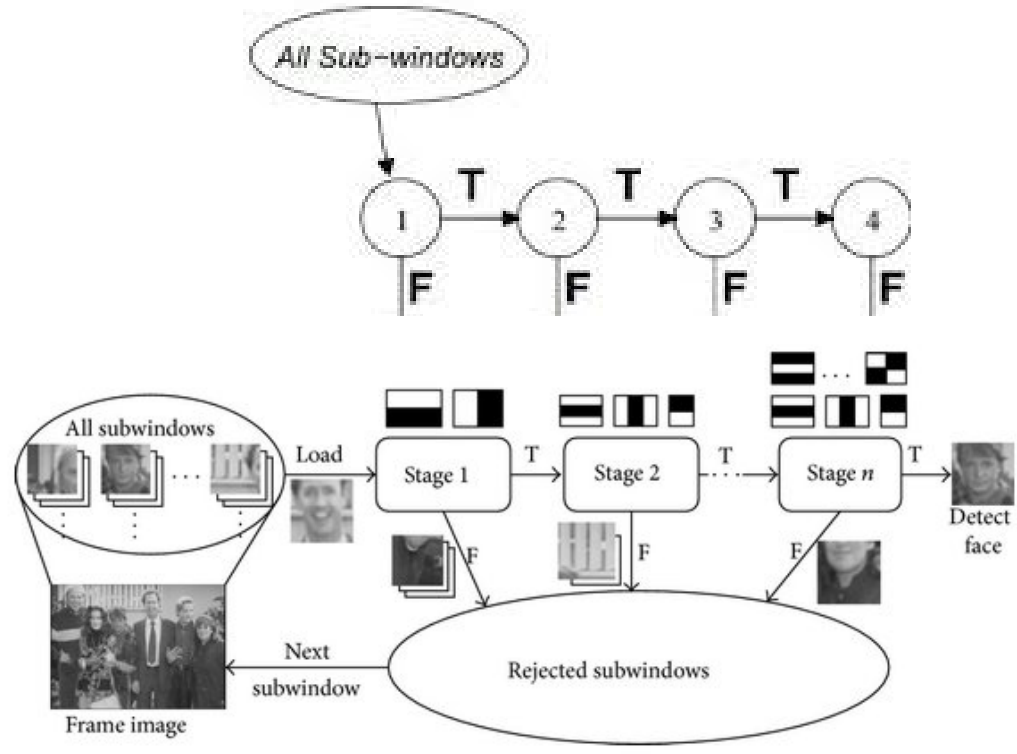

Gambar 5. Cascade Classifier

Tahap cascade classifier

All Sub-window: Semua objek gambar

Load: proses pemisahan objek wajah

Stage 1,2,3: termasuk dalam jenis apa di haar feature

Detectface: pendeteksian wajah

Reject Sub-window: Sub-window yang tidak termasuk objek

\subsection{Flowchart}

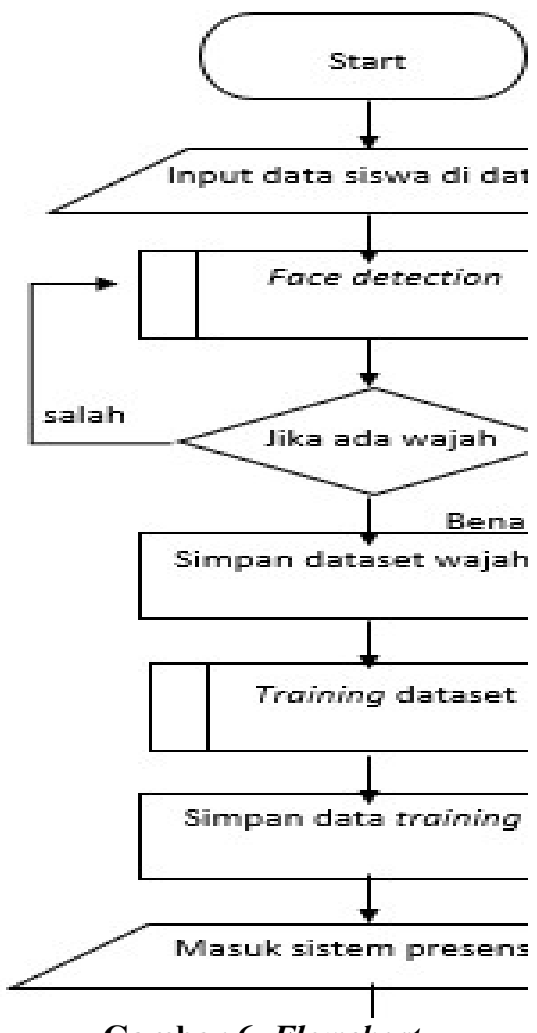

Gambar 6. Flowchart 


\subsection{Peralatan}

Peralatan yang diusulkan dalam sistem baru :

a. Prosesor Inetl Pentium IV

b. Ram 2 GB

c. HDD $250 \mathrm{~GB}$

d. Monitor : 14 inci

e. Keyboard

f. Mouse

g. Raspberry Pi Module

h. Raspberry Pi Camera Module

\subsection{Metode Pengembangan Sistem}

Metode yang digunakan dalam penulisan Tugas Akhir adalah metode prototype. Metode ini cocok digunakan untuk mengembangkan sebuah perangkat yang akan di kembangkan kembali. Metode prototype dimulai dari pengumpulan kebutuhan pelanggan terhadap perangkat lunak yang akan dibuat. Lalu di buatlah program prototype agar pelanggan terbayang dengan apa yang sebenarnya di inginkan.

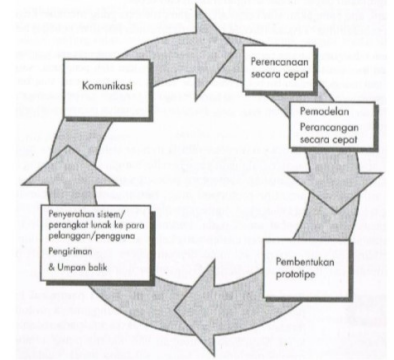

Gambar 7. Metode Pengembangan Sistem Model Prototype (Pressman, 2012)

a. Komunikasi

Pada tahap ini penulis mengumpulkan data awal dan melakukan analisis terhadap kebutuhan user atau pengguna.

b. Perencanaan Secara Cepat

Dalam tahap ini, penulis membuat desain umum yang selanjutnya dikembangkan kembali sebgai bentuk perancangan awal atau desain raspberry pi yang telah dianalisis ke dalam bentuk yang mudah di mengerti oleh user.

c. Pemodelan Perancangan Secara Cepat

Dalam tahap ini penulis membuat perancangan pada sistem yang nantinya akan dibuat menjadi bentuk sebelum tahap implementasi sistem.

d. Pembetukan Prototype

Dalam tahapan ini penulis membuat perangkat prototype termasuk pengujian dan penyempurnaan ke dalam bahasa pemrograman

e. Penyerahan System ke User atau Umpan Balik

Dalam tahap ini, prototype diberikan kepada pengguna untuk evaluasi dan perbaikan apabila kebutuhan atau permintaan user bertambah.

\section{HASIL}

\subsection{Halaman Utama Sistem Presensi}

Halaman utama ini merupakan tampilan dimana siswa melakukan absensi dimana terdiri dari NIS, NAMA dan kelas dari siswa tersebut serta tombol cek untuk memastikan siswa telah absen sebelumnya, serta tombol absen untuk mendeteksi wajah siswa untuk absen. 


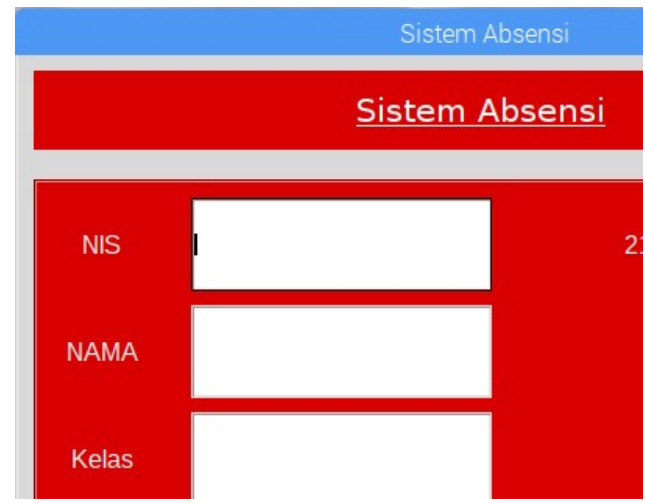

Gambar 8. Halaman Utama Sistem Absensi

\subsection{Halaman Sistem Buttom Cek}

Halaman sistem buttom cek ini berfungsi untuk mengetahui sebelumnya apakah nis, nama dan kelas sudah terdaftar atau belum serta mengetahui apakah sebelumnya sudah absen atau belum.
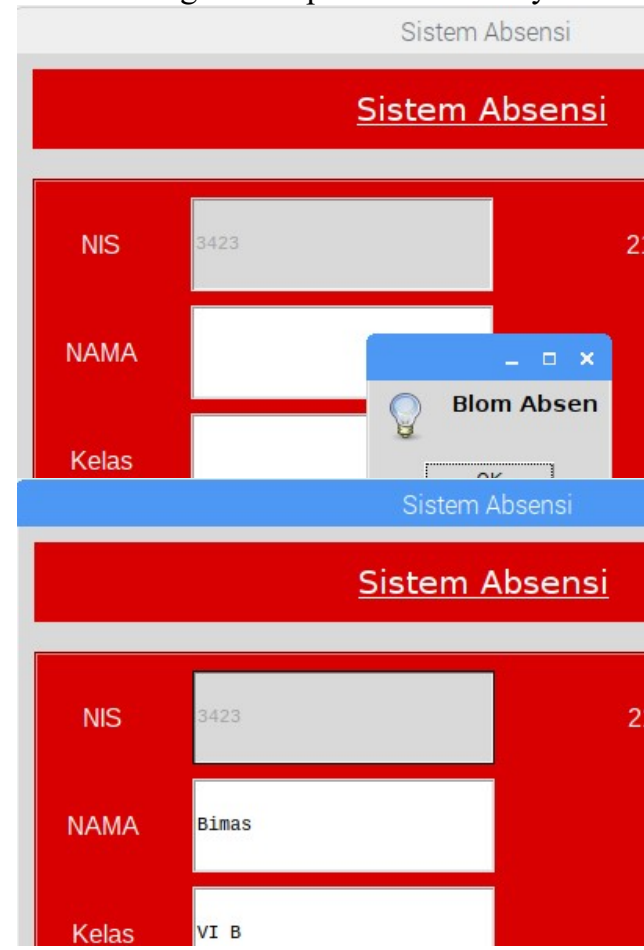

Gambar 9. Halaman Sistem Cek Absen

\subsection{Halaman Sistem Buttom Absen}

Halaman sistem buttom absen ini berfungsi untuk mendeteksi wajah setiap siswa yang datang tepat waktu ataupun telat.

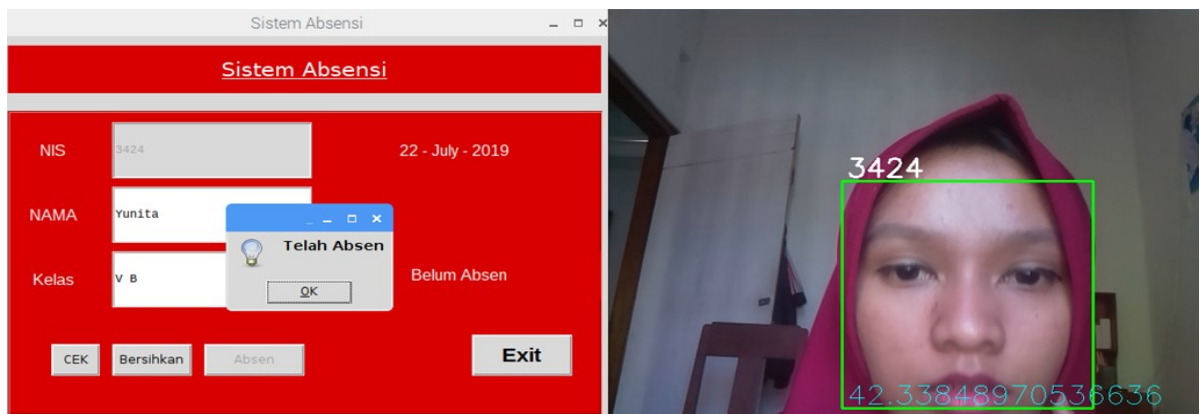

Gambar 10. Halaman Buttom Cek Telah Absen 


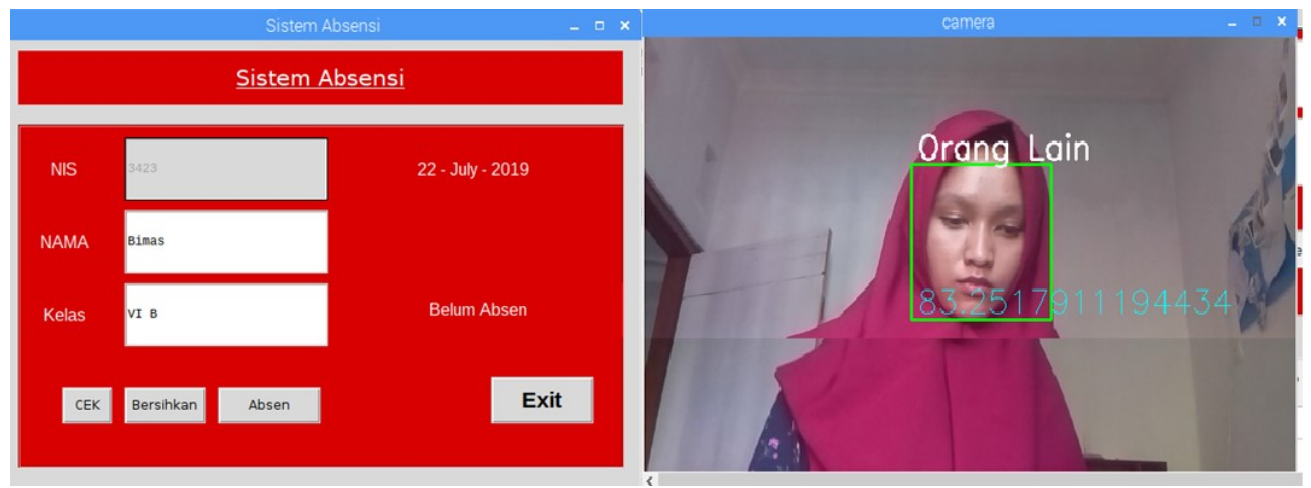

Gambar 11. Halaman Buttom Cek Gagal

\section{KESIMPULAN}

Dari hasil pembuatan sistem yang telah dilakukan maka penulis menarik kesimpulan bahwa :

a. Sistem memudahkan dalam memantau kehadiran seluruh siswa di kelas secara akurat, efisien serta menghemat waktu serta tenaga.

b. Dari hasil pendeteksian wajah menggunakan metode haar cascade classifier ialah sebesar $75 \%$

c. Seluruh sistem terbukti dapat berjalan dengan baik dalam mendeteksi serta mengabsen objek yang ada secara tepat.

\section{DAFTAR PUSTAKA}

[1] d. S. M. S. P. R. A. Apriyana, "Perbandingan Model Sobel, Metode Prewitt dan Metode Robert Untuk Deteksi Tepi Objek pada Aplikasi Pengenalan Bentuk Berbasis Citra Digital," 2013.

[2] R. a. J. M. Lienhart, "An extended set of haar-like features for rapid object detection.," IEEE ICIP , vol. 1, pp. 900-903, 2002.

[3] P. a. M. J. Viola, " Rapid object detection using boosted cascade of simple features," Proceedings IEEE Conf. on Computer Vision and Pattern Recognition, 2001.

[4] M. D. A. d. K. Z. Sanjaya, "Membuat Robot Vision Eyes-Botic bersama Profesor Bolabot menggunakan Mikrorosesor Raspberry Pi dan Pemrograman Python + OpenCv," Bolabot, 2018.

[5] A. Dinata, Physical Computing dengan Raspberry Pi, Jakarta: Elex Media Komputindo, 2017.

[6] A. M. S. M. H. S. ,. S. Rasyid Sindu, "Rancang Bangun Sistem Keamanan dan Pengenalan Objek dalam Ruangan Sebagai Pengganti CCTV dengan Menggunakab Raspberry Pi," Jurnal Teknik Pomits, vol. 2, pp. 2301-9271.

[7] R. S. Pressman, Rekayasa Perangkat Lunak Pendekatan Praktisi Edisi 7, 2012. 